\title{
Corrigendum: A HUPO test sample study reveals common problems in mass spectrometry-based proteomics
}

Alexander W Bell, Eric W Deutsch, Catherine E Au, Robert E Kearney, Ron Beavis, Salvatore Sechi, Tommy Nilsson, John J M Bergeron \& HUPO Test Sample Working Group

Nat. Methods 6, 423-430 (2009); published online 17 May 2009; corrected after print 29 June 2009.

In the version of this article initially published, the author name Steven A. Carr was spelled incorrectly, and the name of an organization described in the text, the HUPO Proteomics Standards Initiative (PSI), was given incorrectly. These errors have been corrected in the PDF and HTML versions of this article.

\section{Erratum: Transposon-mediated genome manipulation in vertebrates}

Zoltán Ivics, Meng Amy Li, Lajos Mátés, Jef D Boeke, Andras Nagy, Allan Bradley \& Zsuzsanna Izsvák Nat. Methods 6, 415-422 (2009); published online 28 May 2009; corrected after print 11 June 2009.

In the version of this article initially published, a part of Figure 1b was incorrectly labeled. The error has been corrected in the HTML and PDF versions of the article. 